\title{
Is platelet inhibition due to thienopyridines increased in elderly patients, in patients with previous stroke and patients with low body weight as a possible explanation of an increased bleeding risk?
}

\author{
N. J. Breet • H. E. van Donkersgoed • \\ J. W. van Werkum • H. J. Bouman • J. C. Kelder • \\ F. Zijlstra $\cdot$ C. M. Hackeng $\cdot$ J. M. ten Berg
}

Published online: 15 April 2011

(C) The Author(s) 2011. This article is published with open access at Springerlink.com

\begin{abstract}
Background The TRITON-TIMI 38 study has identified three subgroups of patients with a higher risk of bleeding during treatment with the thienopyridine prasugrel: patients with a history of stroke or transient ischaemic attack (TIA), patients $\geq 75$ years and patients with a body weight $<60 \mathrm{~kg}$. However, the underlying pathobiology leading to this increased bleeding risk remains to be elucidated. The higher bleeding rate may be due to a stronger prasugrelinduced inhibition of platelet aggregation in these subgroups. The aim of the present study was to determine whether on-treatment platelet reactivity is lower in these risk subgroups as compared with other patients in a large cohort on the thienopyridine clopidogrel undergoing elective coronary stenting.

Methods A total of 1069 consecutive patients were enrolled. On-clopidogrel platelet reactivity was measured in
\end{abstract}

N. J. Breet · J. W. van Werkum • H. J. Bouman · J. C. Kelder • J. M. ten Berg $(\bowtie)$

Department of Cardiology, St. Antonius Hospital,

PO Box 2500, 3435 CM Nieuwegein, the Netherlands

e-mail: j.ten.berg@antoniusziekenhuis.nl

N. J. Breet $\cdot$ H. E. van Donkersgoed · J. W. van Werkum •

H. J. Bouman · J. C. Kelder C. M. Hackeng · J. M. ten Berg

St. Antonius Center for Platelet Function Research,

Nieuwegein, the Netherlands

F. Zijlstra

Department of Cardiology, Erasmus Medical Centre,

Rotterdam, the Netherlands

C. M. Hackeng

Department of Clinical Chemistry, St. Antonius Hospital,

Nieuwegein, the Netherlands parallel by light transmittance aggregometry, the VerifyNow ${ }^{\circledR}$ P2Y12 assay and the PFA-100 collagen/ADP cartridge.

Results Fourteen patients (1.5\%) had a prior history of stroke or TIA, 138 patients $(14.5 \%)$ were older than 75 years and 30 patients (3.2\%) had a body weight $<60 \mathrm{~kg}$. Age $\geq 75$ years and a history of stroke were independent predictors of a higher on-treatment platelet reactivity. In contrast, a body weight $<60 \mathrm{~kg}$ was significantly associated with a lower on-treatment platelet reactivity.

Conclusion In two high-risk subgroups for bleeding, patients $\geq 75$ years and patients with previous stroke, onclopidogrel platelet reactivity is increased. In contrast, in patients with a low body weight, on-clopidogrel platelet reactivity is decreased, suggesting that a stronger response to a thienopyridine might only lead to more bleeds in patients with low body weight

Keywords Clopidogrel $\cdot$ Platelet reactivity

\section{Introduction}

Dual antiplatelet therapy with aspirin and the thienopyridine clopidogrel is the therapy of choice in patients undergoing percutaneous coronary intervention (PCI) with stent implantation [1, 2]. However, despite this treatment ischaemic events still occur, and multiple studies have clearly demonstrated a relationship between the magnitude of on-treatment platelet reactivity and the occurrence of atherothrombotic events [3-8]. Therefore, novel antiplatelet agents with more consistent response rates among patients 
have been introduced. One of these is the thienopyridine prasugrel which, similar to clopidogrel, is a specific, irreversible adenosine diphosphate (ADP)-receptor antagonist, but it is faster acting and a more potent platelet inhibitor. The Trial to Assess Improvement in Therapeutic Outcomes by Optimising Platelet Inhibition with PrasugrelThrombolysis in Myocardial Infarction 38 (TRITON-TIMI 38) demonstrated a significant risk reduction for the occurrence of thrombotic events in patients with an acute coronary syndrome (ACS) undergoing PCI with prasugrel as compared with clopidogrel [9]. This reduction, however, was counterbalanced by a $30 \%$ increased risk of bleeding, suggesting a link between platelet reactivity inhibition and bleeding $[10,11]$.

Three subgroups of patients were identified as having less clinical efficacy from prasugrel and greater absolute risk of bleeding than the overall cohort. These included (1) patients with a prior history of stroke or transient ischaemic attack (TIA), (2) the elderly ( $\geq 75$ years of age), and (3) patients with a body weight $<60 \mathrm{~kg}$ [9]. However, the underlying pathobiology leading to this increased bleeding risk remains to be elucidated.

It has been hypothesised that the higher bleeding rate may be due to a stronger prasugrel-induced inhibition of ADPinduced platelet aggregation in these subgroups. Since prasugrel has been introduced only recently, few pharmacodynamic data are available. However, in the POPular study (The Do Platelet Function Assays Predict Clinical Outcomes in Clopidogrel Pretreated Patients Undergoing Elective PCI study), the influence of the other thienopyridine clopidogrel on the inhibition of platelet reactivity was determined in patients undergoing elective coronary stent implantation. The aim of the present sub-analysis study was to establish whether the on-clopidogrel platelet reactivity is lower in the three subpopulations at risk for bleeding as compared with in other patients in a large cohort of patients on clopidogrel undergoing elective coronary stenting.

\section{Methods}

Study population

The POPular study was a prospective, observational study that included consecutive patients with established coronary artery disease scheduled for elective PCI with stent implantation. The entry and exclusion criteria were described in the original publication [3]. All patients had been on dual antiplatelet therapy with clopidogrel and low-dose aspirin of $80-100 \mathrm{mg}$ daily for at least 10 days, unless they were on long-term treatment with coumarin derivates. This study complied with the Declaration of Helsinki and was approved by the local institutional review board. Written informed consent was obtained from every patient prior to elective PCI.

Blood sampling and platelet function testing

Prior to heparinisation, whole blood was drawn from the femoral or radial artery sheath. After discarding the first $10 \mathrm{ml}$ of blood, samples were collected into citrated tubes (3.2\% for light transmittance aggregometry (LTA) and the VerifyNow ${ }^{\circledR}$ system and $3.8 \%$ for PFA). The magnitude of platelet reactivity was measured using three platelet function tests in parallel; the platelet function analyser (PFA-100) and 'classical' LTA. All methods were performed between $30 \mathrm{~min}$ and $2 \mathrm{~h}$ after blood collection.

\section{Light transmittance aggregometry}

LTA was quantified in non-adjusted platelet-rich plasma on a four-channel APACT 4004 aggregometer (LABiTec, Arensburg, Germany). Platelet-poor plasma was set as $100 \%$ aggregation, and maximal (peak) platelet aggregation (\%) was measured spontaneously and after stimulation by ADP in final concentrations of 5 and $20 \mu \mathrm{mol} / \mathrm{L}$.

\section{The VerifyNow ${ }^{\circledR}$ P2Y12 assay}

The VerifyNow ${ }^{\circledR}$ P2Y12 assay (Accumetrics, Inc, San Diego, USA) is an automated whole blood, cartridgebased method to determine the magnitude of platelet agglutination as induced by $\mathrm{ADP} /$ prostaglandin $\mathrm{E}_{1}$ [12]. The results are reported in P2Y12 Reaction Units.

\section{PFA-100}

The PFA-100 System (Siemens Healthcare Diagnostics Products $\mathrm{GmbH}$, Germany) measures platelet function, in particular adhesion and aggregation, in whole blood under high shear conditions $\left(5000 \mathrm{~s}^{-1}\right)$ [13]. The time needed to form a platelet plug occluding the aperture cut into a membrane coated with collagen/ADP, an agonist, was determined and reported as closure time in seconds, which is inversely related to platelet reactivity. A closure time of $>300 \mathrm{~s}$ was referred to as 'non-closure'.

\section{Statistical analysis}

Continuous variables are presented as mean (SD). Categorical data are reported as frequencies (percentages). Categorical variables were compared using the $\chi^{2}$ test or Fisher's exact test when frequencies were $<5$. The distribution of variables was determined by the Kolmogorov-Smirnov goodness-offit test. Normally distributed continuous variables were compared with a two-sided unpaired $t$ test. 
Logistic regression modelling was performed to identify independent correlates of the magnitude of platelet reactivity and to adjust for potential confounders. Being part of a high-risk group was entered as a dichotomous variable. All univariate variables with a $p$ value $<0.10$ were included in multivariable analysis (binary logistic regression).

\section{Results}

Patient characteristics

A total of 1069 consecutive patients were enrolled, of whom 951 were on aspirin $>10$ days. The latter comprised the present study population. Owing to irregularities in platelet assay supply, as well as technical failure in a minority of platelet function tests, not all platelet function assays were performed in every patient.

Baseline characteristics of the total population are depicted in Table 1. Fourteen patients (1.5\%) had a history of stroke or TIA, 138 patients $(14.5 \%)$ were older than 75 years of age and 30 patients $(3.2 \%)$ had a body weight $<60 \mathrm{~kg}$. Patients $\geq 75$ years were more often female and smoker and had a lower haemoglobin. They were less often treated with statins and the proportion of hypercholesterolaemia, renal failure and an impaired ejection fraction was higher. Patients with a history of stroke or TIA more frequently received a loading dose of clopidogrel and more often had a previous history of coronary artery bypass grafting. Patient with a body weight $<60 \mathrm{~kg}$ were significantly older, had lower haemoglobin and were less often treated with statins and $\beta$-blockade. The proportion of females was higher in this group, the frequency of diabetes mellitus and hypertension was lower and the minimal stent diameter was smaller.

Old age as risk factor for low platelet reactivity

Elderly patients $\geq 75$ years had a significantly higher magnitude of on-treatment platelet reactivity as compared with patients $<75$ years, regardless of the platelet function test used. (Fig. 1a; Table 2) After adjustment for factors known to influence platelet function (diabetes mellitus, smoking, gender, concomitant use of proton pump inhibitors and the administration of a loading dose of clopidogrel), an age $\geq 75$ years remained an independent predictor of a higher magnitude of platelet reactivity, except when $20 \mu \mathrm{mol} / \mathrm{L}$ induced LTA was used (Table 2).

Cerebrovascular accident as risk factor for low platelet reactivity

In patients with a history of stroke or TIA, the magnitude of platelet reactivity was significantly higher as compared
Table 1 Baseline characteristics

Total population

\begin{tabular}{|c|c|}
\hline \multicolumn{2}{|l|}{ Clinical parameters } \\
\hline Age (years) & $64 \pm 10.6$ \\
\hline BMI $\left(\mathrm{kg} / \mathrm{m}^{2}\right)$ & $27.3 \pm 3.9$ \\
\hline Gender (male) & $717 / 951(75.4 \%)$ \\
\hline Hypertension & $737 / 951(77.5 \%)$ \\
\hline Hypercholesterolaemia & $769 / 951(80.9 \%)$ \\
\hline Diabetes mellitus & $175 / 951(18.4 \%)$ \\
\hline Family history & $580 / 951(61.0 \%)$ \\
\hline Current smoking & $107 / 951(11.3 \%)$ \\
\hline Impaired ejection fraction & $133 / 951(14.0 \%)$ \\
\hline Renal insufficiency & $72 / 951(7.6 \%)$ \\
\hline Prior myocardial infarction & $519 / 951(54.6 \%)$ \\
\hline Prior PCI & $304 / 951(32.0 \%)$ \\
\hline Prior $\mathrm{CABG}$ & $93 / 951(9.8 \%)$ \\
\hline \multicolumn{2}{|l|}{ Medication } \\
\hline Loading dose clopidogrel & $489 / 951(51.4 \%)$ \\
\hline Statin & $767 / 951(80.7 \%)$ \\
\hline$\beta$-blocker & 733/951 (77.1\%) \\
\hline ACE inhibitor & $345 / 951(36.3 \%)$ \\
\hline Proton pump inhibitor & $270 / 951(28.4 \%)$ \\
\hline Calcium channel blocker & $365 / 951(38.4 \%)$ \\
\hline Oral anti-diabetic agents & $62 / 951(6.5 \%)$ \\
\hline Coumarin derivatives & $24 / 951(2.5 \%)$ \\
\hline \multicolumn{2}{|l|}{ Laboratory parameters } \\
\hline Platelet count $\left(\times 10^{9}\right)$ & $273.4 \pm 78.8$ \\
\hline White blood cell count $\left(\times 10^{9}\right)$ & $7.7 \pm 2.3$ \\
\hline Haemoglobin $(\mathrm{mmol} / \mathrm{L})$ & $8.6 \pm 2.2$ \\
\hline \multicolumn{2}{|l|}{ Procedural parameters } \\
\hline No. of stents implanted & $1489 / 9501.57$ \\
\hline No. of lesions treated & $1317 / 9511.38$ \\
\hline Minimal stent diameter $(\mathrm{mm})$ & $3.1 \pm 0.8$ \\
\hline Total stent length (mm) & $28.3 \pm 17.1$ \\
\hline Bifurcation lesion & $32 / 951(3.4 \%)$ \\
\hline Drug-eluting stent & $604 / 946(63.8 \%)$ \\
\hline Left anterior descending artery & $450 / 951(47.3 \%)$ \\
\hline Graft & $28 / 951(2.9 \%)$ \\
\hline
\end{tabular}

$A C E$ angiotensin-converting enzyme, $B M I$ body mass index, $C A B G$ coronary artery bypass grafting

with patients without a previous cerebrovascular accident when platelet reactivity was established using LTA (both 5 and $20 \mu \mathrm{mol} / \mathrm{L}$ ADP-induced aggregation) (Fig. 1b; Table 2). After adjustment for potential confounders, a history of stroke or TIA remained an independent predictor of a higher level of aggregation. In contrast, no significant difference was found between the group with and without a history of stroke or TIA when platelet reactivity was assessed using the VerifyNow ${ }^{\circledR}$ P2Y12 assay or the PFA COL/ADP cartridge (Table 2). 

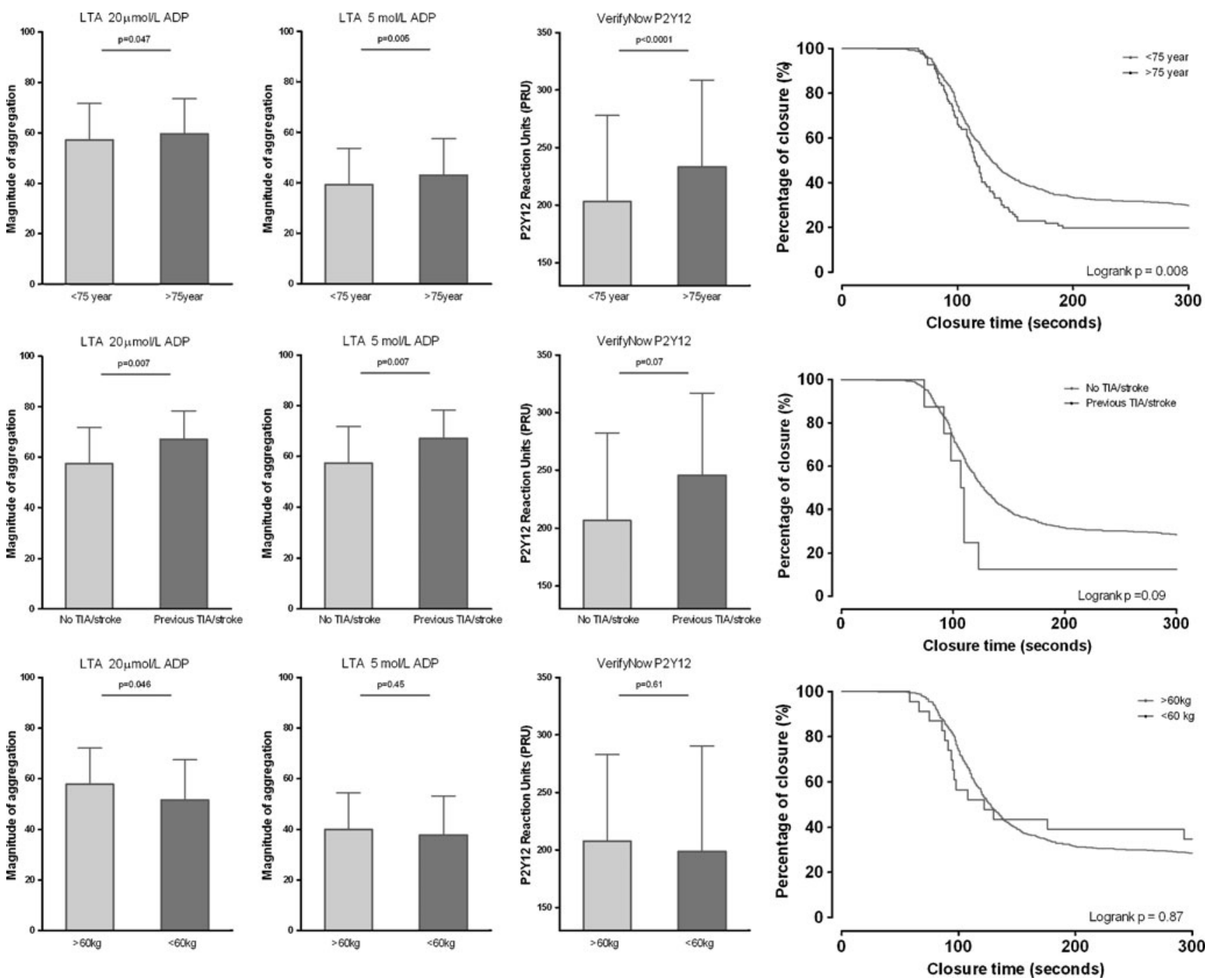

Fig. 1 Magnitude of platelet reactivity. Magnitude of platelet reactivity according to the three tests used. Since the PFA- $100^{\circledR}$ System confines detection of a closure time to a 300 -s window, the results of the PFA- $100^{\circledR}$ System are depicted as a cumulative Kaplan-
Meier time-to-aperture-closure plot and a log-rank test was used. a In patients $<75$ years vs. patients $\geq 75$ years of age. $\mathbf{b}$ In patients with a history of TIA or stroke vs. patients without a history of TIA or stroke. c In patients $<60 \mathrm{~kg}$ vs. patients $\geq 60 \mathrm{~kg}$
Low body weight as risk factor for low platelet reactivity

Aggregation as measured by $20 \mu \mathrm{mol} / \mathrm{L}$ ADP-induced LTA was significantly lower in patients with a body weight $<60 \mathrm{~kg}$ as compared with patients with a higher body weight. None of the other tests identified significant differences between patients with a low body weight and patients with a body weight $>60 \mathrm{~kg}$ (Fig. 1c, Table 2). After adjustment for potential confounding factors, lower body weight remained significantly associated with an intensified platelet response to clopidogrel as established by either $20 \mu \mathrm{mol} / \mathrm{L}$ ADP-induced LTA and became significant when measured with the VerifyNow ${ }^{\circledR}$ P2Y12 assay (Table 2).

\section{Discussion}

Whereas TRITON-TIMI 38 demonstrated that prasugrel, a thienopyridine resulting in lower on-treatment platelet reactivity as compared with clopidogrel, was associated with less recurrent atherothrombotic events in ACS patients undergoing PCI, an increased risk of bleeding was observed in patients treated with prasugrel [9]. The presence of a therapeutic window was already acknowledged by Paracelsus, who stated as early as in the fifteenth century that 'All drugs are poisons, the benefit depends on the dosage' [14]. There is currently a growing body of evidence supporting the association between bleeding and adverse outcomes, including myocardial infarction, stroke and death 
Table 2 Magnitude of platelet reactivity

Magnitude of platelet reactivity in the elderly

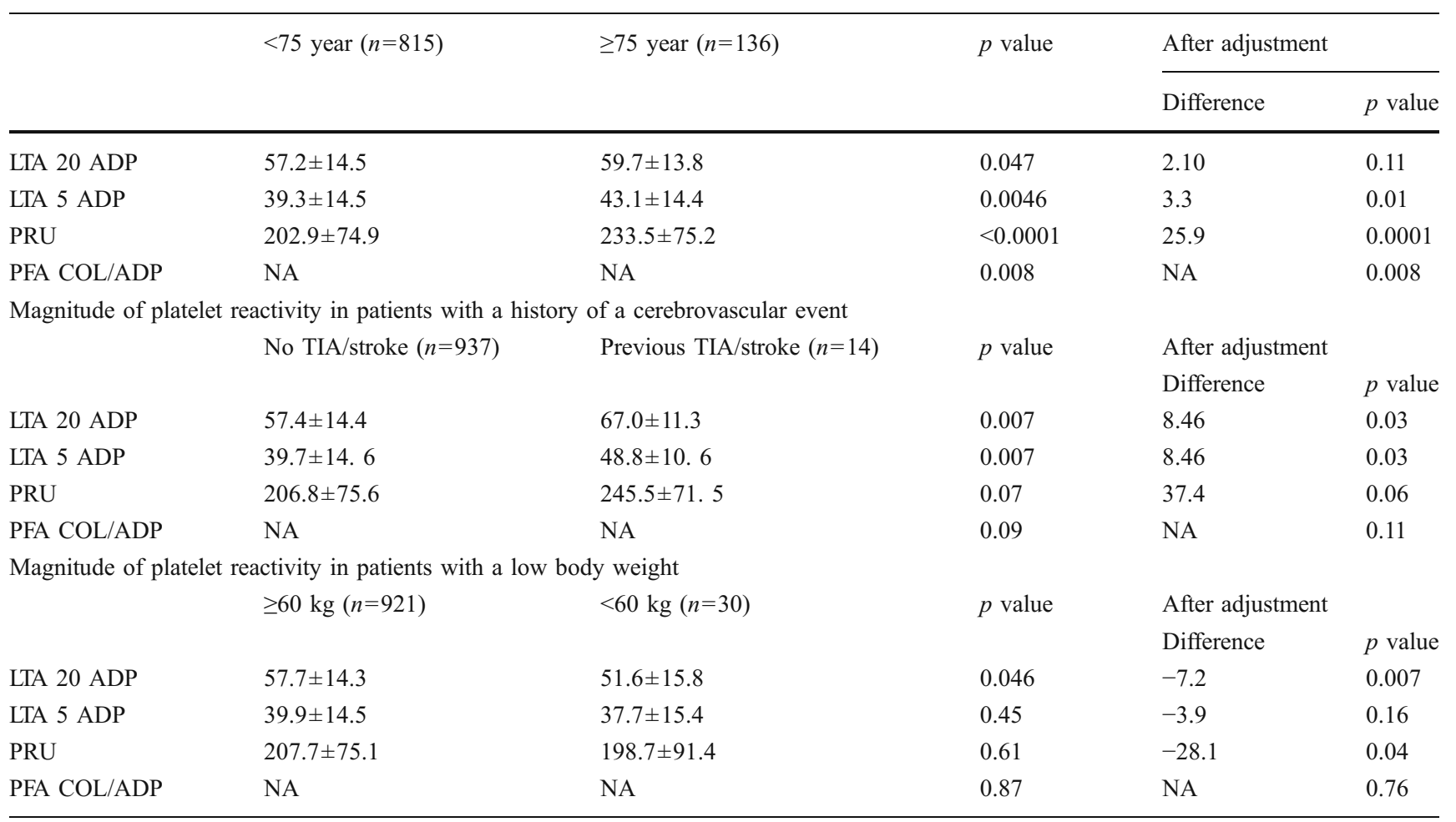

LTA light transmittance aggregometry, $N A$ not applicable, $P R U \mathrm{P} 2 \mathrm{Y} 12$ reaction units, $P F A C O L / A D P$ platelet function analyser using the collagen/ ADP cartridge

[15-17], and several studies have suggested a link between the inhibition of platelet reactivity and the occurrence of bleeding [10, 18-20]. Thus, the identification of a window of platelet inhibition that on the one hand prevents atherothrombotic events and on the other hand does not lead to an increase in bleeding events, is of utmost importance [21].

The TRITON-TIMI 38 study has identified three subgroups of patients with a higher risk of bleeding during treatment with prasugrel: (1) patients with a prior history of stroke or TIA, (2) the elderly ( $>75$ years of age), and (3) patients with a body weight less $<60 \mathrm{~kg}$ [9]. However, the underlying pathobiology leading to this increased bleeding risk remains to be elucidated. It has been hypothesised that the higher bleeding rate might be the consequence of a stronger prasugrel-induced inhibition of ADP-induced platelet aggregation in these subgroups. Since prasugrel was introduced only recently, few pharmacodynamic data are available. The present study, with the aim to determine whether on-clopidogrel platelet reactivity is lower in these risk subgroups as compared with other patients, demonstrated that in the two high-risk subgroups for bleeding, patients $>75$ years of age and patients with previous stroke, on-treatment platelet reactivity is contrarily increased. However, in the third high-risk subgroup for bleeding, patients with a low body weight, on-treatment platelet reactivity is indeed decreased. When these data are applied to the hypothesis that prasugrel leads to a stronger platelet inhibition, it seems that in TRITON-TIMI 38, a stronger response to prasugrel might have only led to more bleeds in patients with low body weight.

These observations are in line with results from a recent analysis of 16 phase-I clinical pharmacological studies performed in healthy patients. In this analysis, no effect of advanced age on the availability of the active metabolite of prasugrel was perceived [22]. On the contrary, in the TRITON-TIMI 38 , patients $\geq 75$ years had $19 \%$ higher exposure to the active metabolite as compared with those $<75$ years and even $25 \%$ higher exposure as compared with patients $<60$ years of age [23]. However, in the latter the concentration of the active metabolite was not measured, but estimated from its inactive metabolite. In contrast, body weight had the greatest influence on exposure to the active metabolite of prasugrel in both clinical pharmacology studies and the TRITON-TIMI 38, with an increase in exposure as body weight decreased. Exposure was $40 \%$ higher in individuals $<60 \mathrm{~kg}$ as compared with those $\geq 60 \mathrm{~kg}[22,23]$. Modelling data suggest that decreasing the maintenance dose of prasugrel to $5 \mathrm{mg}$ in these subjects would reduce exposure to the active metabolite to levels 
consistent with those $<75$ years and $\geq 60 \mathrm{~kg}$ [22]. Both European and American regulatory agents therefore recommend a daily dose of $5 \mathrm{mg}$ in patients $<60 \mathrm{~kg}$. For patients $\geq 75$ years, the US Food and Drug Administration advises that prasugrel is generally not recommended, but might be considered in patients at high risk of recurrent atherothrombotic events at a maintenance dose of $10 \mathrm{mg}$ in those $\geq 60 \mathrm{~kg}$ [23]. On the contrary, the European Medicines Agency recommends that prasugrel is avoided in the elderly, but if used, the dose should be halved to $5 \mathrm{mg}$ [23]. Taking the findings from the present study into account and the fact that elderly patients have a higher risk of bleeding as compared with younger individuals, even when not on thienopyridine therapy [24], we do not consider prasugrel to result in an excess in platelet inhibition, thereby accounting for the increased bleeding risk in this population.

In conclusion, the results from the present analysis confirmed previous studies and identified body weight as the most influential covariate on the magnitude of ADPinduced platelet reactivity, which might have implications for prasugrel maintenance dose in daily clinical practice.

Open Access This article is distributed under the terms of the Creative Commons Attribution Noncommercial License which permits any noncommercial use, distribution, and reproduction in any medium, provided the original author(s) and source are credited.

\section{References}

1. Steinhubl SR, Berger PB, Mann III JT, et al. Early and sustained dual oral antiplatelet therapy following percutaneous coronary intervention: a randomized controlled trial. JAMA. 2002;288:241120.

2. Mehta SR, Yusuf S, Peters RJ, et al. Effects of pretreatment with clopidogrel and aspirin followed by long-term therapy in patients undergoing percutaneous coronary intervention: the PCI-CURE study. Lancet. 2001;358:527-33.

3. Breet NJ, van Werkum JW, Bouman HJ, et al. Comparison between platelet function tests in predicting clinical outcome in patients undergoing coronary stent placement. JAMA. 2010;303:754-62.

4. Matetzky S, Shenkman B, Guetta V, et al. Clopidogrel resistance is associated with increased risk of recurrent atherothrombotic events in patients with acute myocardial infarction. Circulation. 2004;109:3171-5.

5. Gurbel PA, Bliden KP, Guyer K, et al. Platelet reactivity in patients and recurrent events post-stenting: results of the PREPARE POST-STENTING Study. J Am Coll Card. 2005;46:1820-6.

6. Marcucci R, Gori AM, Paniccia R, et al. Cardiovascular death and nonfatal myocardial infarction in acute coronary syndrome patients receiving coronary stenting are predicted by residual platelet reactivity to ADP detected by a point-of-care assay: a 12month follow-up. Circulation. 2009;119:237-42.

7. Geisler $\mathrm{T}$, Langer $\mathrm{H}$, Wydymus $\mathrm{M}$, et al. Low response to clopidogrel is associated with cardiovascular outcome after coronary stent implantation. Eur Heart J. 2006;27:2420-5.

8. Combescure C, Fontana P, Mallouk N, et al. Clinical implications of clopidogrel non-response in cardiovascular patients: a systematic review and meta-analysis. J Thromb Haemost. 2010;8:923-33.

9. Wiviott SD, Braunwald E, McCabe $\mathrm{CH}$, et al. Prasugrel versus clopidogrel in patients with acute coronary syndromes. N Engl J Med. 2007;357:2001-15.

10. Mokhtar OA, Lemesle G, Armero S, et al. Relationship between platelet reactivity inhibition and non-CABG related major bleeding in patients undergoing percutaneous coronary intervention. Thromb Res. 2010;126:e147-9.

11. Bonello L, De Labriolle A, Scheinowitz M, et al. Emergence of the concept of platelet reactivity monitoring of response to thienopyridines. Heart. 2009;95:1214-9.

12. van Werkum JW, Harmsze AM, Elsenberg EH, et al. The use of the VerifyNow system to monitor antiplatelet therapy: a review of the current evidence. Platelets. 2008;19:479-88.

13. van Werkum JW, Hackeng CM, Smit JJ, et al. Monitoring antiplatelet therapy with point-of-care platelet function assays: a review of the evidence. Future Cardiol. 2008;8:33-55.

14. Paracelsus WP. An Introduction to Philosophical. In: Medicine in the Era of the Renaissance. Basel: Karger; 1982.

15. Stone GW, Witzenbichler B, Guagliumi G, et al. Bivalirudin during primary PCI in acute myocardial infarction. N Engl J Med. 2008;358:2218-30.

16. Yusuf S, Mehta SR, Chrolavicius S, et al. Comparison of fondaparinux and enoxaparin in acute coronary syndromes. $\mathrm{N}$ Engl J Med. 2006;354:1464-76.

17. Bhatt DL. Intensifying platelet inhibition-navigating between Scylla and Charybdis. N Engl J Med. 2007;357:2078-81.

18. Sibbing D, Schulz S, Braun S, et al. Antiplatelet effects of clopidogrel and bleeding in patients undergoing coronary stent placement. J Thromb Haemost. 2010;8:250-6.

19. Sibbing D, Steinhubl SR, Schulz S, et al. Platelet aggregation and its association with stent thrombosis and bleeding in clopidogreltreated patients: initial evidence of a therapeutic window. J Am Coll Cardiol. 2010;56:317-8.

20. Cuisset T, Cayla G, Frere C, et al. Predictive value of posttreatment platelet reactivity for occurrence of post-discharge bleeding after non-ST elevation acute coronary syndrome. Shifting from antiplatelet resistance to bleeding risk assessment? EuroIntervention. 2009;5:325-9.

21. Bonello L, Tantry US, Marcucci R, et al. Consensus and future directions on the definition of high on-treatment platelet reactivity to adenosine diphosphate. J Am Coll Cardiol. 2010;56:919-33.

22. Small DS, Li YG, Ernest CS, et al. Integrated analysis of pharmacokinetic data across multiple clinical pharmacology studies of prasugrel, a new thienopyridine antiplatelet agent. J Clin Pharmacol. 2010;51:321-32.

23. Wiviott SD, Antman EM, Prasugrel BE. Prasugrel. Circulation. 2010;122:394-403.

24. Franchini M. Hemostasis and aging. Crit Rev Oncol Hematol. 2006;60:144-51. 